\title{
Optimisation of organosolv pretreatment for the extraction of polyphenols from spent coffee waste and subsequent recovery of fermentable sugars
}

\author{
Rajeev Ravindran \\ Technological University Dublin, rajeev.ravindran@tudublin.ie \\ Claire Desmond \\ Technological University Dublin \\ Swarna Jaiswal \\ Technological University Dublin, swarna.jaiswal@tudublin.ie
}

See next page for additional authors

Follow this and additional works at: https://arrow.tudublin.ie/schfsehart

Part of the Food Science Commons

\section{Recommended Citation \\ Rajeev Ravindran, Claire Desmond, Swarna Jaiswal, Amit K. Jaiswal, Optimisation of organosolv pretreatment for the extraction of polyphenols from spent coffee waste and subsequent recovery of fermentable sugars, Bioresource Technology Reports, Volume 3, 2018, Pages 7-14, ISSN 2589-014X, DOI: 10.1016/j.biteb.2018.05.009.}

This Article is brought to you for free and open access by the School of Food Science and Environmental Health at ARROW@TU Dublin. It has been accepted for inclusion in Articles by an authorized administrator of ARROW@TU Dublin. For more information, please contact arrow.admin@tudublin.ie, aisling.coyne@tudublin.ie, gerard.connolly@tudublin.ie.

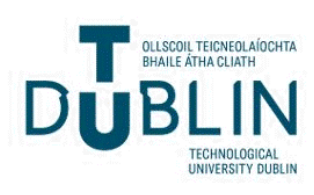




\section{Authors}

Rajeev Ravindran, Claire Desmond, Swarna Jaiswal, and Amit Jaiswal

This article is available at ARROW@TU Dublin: https://arrow.tudublin.ie/schfsehart/452 


\title{
Optimisation of organosolv pretreatment for the extraction of polyphenols from spent coffee waste and subsequent recovery of fermentable sugars
}

\author{
Rajeev Ravindran ${ }^{\mathrm{a}}$, Claire Desmond ${ }^{\mathrm{a}}$, Swarna Jaiswal ${ }^{\mathrm{b}}$, Amit K. Jaiswal ${ }^{\mathrm{a}, *}$ \\ ${ }^{a}$ School of Food Science and Environmental Health, College of Sciences and Health, Dublin Institute of Technology, Cathal Brugha Street, Dublin 1, Ireland \\ ${ }^{\mathrm{b}}$ Centre for Research in Engineering and Surface Technology, FOCAS Institute, Dublin Institute of Technology, Kevin Street, Dublin 8, Ireland
}

\section{A R T I C L E I N F O}

\section{Keywords:}

Lignocellulose

Polyphenol extraction

Spent coffee waste

Modified organosolv pretreatment

Reducing sugar

\begin{abstract}
A B S T R A C T
In the present study, organosolv pretreatment strategy was modified for the comprehensive utilisation of spent coffee waste (SCW) for polyphenol extraction and reducing sugar production. A response surface design involving four factors viz. ethanol concentration, temperature, time and $\mathrm{H}_{2} \mathrm{SO}_{4}$ concentration was created for optimisation of polyphenol extraction from SCW. 11.2 mg GAE of polyphenol content/g of SCW was obtained using ethanol $(68 \% \mathrm{v} / \mathrm{v})$ at $51{ }^{\circ} \mathrm{C}$ for $45 \mathrm{~min}$ in the presence of $1.5 \% \mathrm{H}_{2} \mathrm{SO}_{4}$ as catalyst. Furthermore, 13.78 of QE of Total Flavonoid Content/g of SCW was obtained following this process which was 7.6-fold higher than control (1.81 QE/g of SCW). Lignin removal of $24.4 \%$ was achieved following modified organosolv protocol. Enzymatic hydrolysis of pretreated SCW yielded $29.05 \mathrm{mg} / \mathrm{g}$ of total reducing sugar, which was 1.27-fold higher than control $(22.8 \mathrm{mg} / \mathrm{g})$. XRD, FTIR, and DSC profiles of the pretreated substrates were analysed for various changes incurred in pretreated SCW.
\end{abstract}

\section{Introduction}

Coffee is one of the most popular beverages consumed all over the world. With such popular demand coffee, has become the second most traded commodity after petroleum. Spent coffee waste is the solid residue obtained because of coffee brewing. With the global coffee production increasing by $17 \%$ from 2002 to 2014 the accumulation, treatment and disposal of spent coffee waste (SCW) poses a serious problem. The International Coffee Organisation estimates that 8.5 billion kg of coffee is produced every year (Scully et al., 2016). The EU is a major consumer of coffee. Since being considered as an industrial waste product SCW has no commercial value and more often than not end up being used as landfill and for composting. Albeit being a plant-based material SCW cannot be used as an animal feed supplement due to the presence of tannins, which undermines its nutritional activity (Cruz et al., 2012). However, 'The New Waste Framework Directive' was initiated in 2008/09 by the EU with the intention of curbing food and food industry waste was promoting its recycling and reuse for the initiation and sustaining of new industries (Ravindran and Jaiswal, 2016).

SCW is a lignocellulosic material and essentially consists of polysaccharide polymers and phenolic polymers. Unlike other lignocellulosic residues it also contains proteins and lipids. The polysaccharide fraction in SCW is higher in hemicellulose content as opposed to cellulose content which makes it different from other lignocellulosic feedstocks. The heterogenous nature of hemicellulose makes SCW rich in other monosaccharides such as galactose, arabinose and mannose apart from glucose (Campos-Vega et al., 2015). This makes it a viable candidate for a spectrum of value added products such as bioethanol, crude enzyme, monomeric sugars, activated carbon, sorbent materials etc. (Go et al., 2016). In addition to its high polysaccharide content SCW is rich in numerous phenolic compounds with antioxidant activity, making it a potential feedstock for the recovery of natural antioxidants (Panusa et al., 2013).

Biorefinery is a novel concept that aims at the total utilisation of all fractions of a raw material to minimise waste formation at the end of the production process (Mohan et al., 2016). A biorefinery model for SCW would mean the utilisation of lignocellulose fraction for maximised reducing sugar recovery augmented by a simultaneous process to extract the polyphenol content with antioxidant activity. Lately, spent coffee grounds have been reported to support the production of lignocellulolytic enzymes by white-rot fungi by solid state fermentation (Montoya et al., 2012). However, the extraction of reducing sugar would mean devising pretreatment and hydrolytic methods involving cellulytic enzymes (Ma et al., 2015). Pretreatments are necessary methodologies that would remove components of lignocellulose that cause recalcitrance and enhance the ease of hydrolysis for maximum sugar release. The nature of the pretreatment can vary from being

\footnotetext{
* Corresponding author.

E-mail addresses: amit.jaiswal@dit.ie, akjaiswal@outlook.com (A.K. Jaiswal).
} 
physical to chemical and can also involve biological agents such as enzymes and microbes. These processes may involve high temperatures and pressure and may utilise solvents that may be mild or corrosive in nature. Subjecting lignocellulosic substrates to pretreatments may result in the loss of components, variations in crystallinity and the formation of inhibitory compounds such as furfural and hydroxy methyl furfural depending upon the involvement of heat (Jönsson and Martín, 2016).

Organosolv is a pretreatment method that utilises the combined power of solvents and heat to break down the complex structure of lignocellulose. Most of the solvent used in the organosolv process and organic in nature. Some examples of solvents used in organosolv process include methanol, ethanol and acetone (Zhao et al., 2009). This pretreatment has been widely documented to enhance enzymatic hydrolysis of several lignocellulose residues such as sugar cane bagasse, Pinus radiata, wheat straw and loblolly pine, leading to subsequent production of second generation biofuels (Araque et al., 2008; Sannigrahi et al., 2010; Sun and Chen, 2008). Organosolv is a delignification process that involves alcohols such as methanol at temperatures $<180^{\circ} \mathrm{C}$. The process can take place in the presence or absence of a catalyst which can be mineral acids to metal ions such as calcium or magnesium. The lignin removed and the solvent utilised can be recovered by simple distillation (Zhao et al., 2009).

Solid-liquid extraction is one of the most widely used methods for extraction of polyphenols from plant sources (Mussatto et al., 2011). Interestingly, the extraction and recovery of polyphenols with antioxidant activity from SCW also utilise primary alcohols such as methanol and ethanol. Several factors influence the efficient extraction of polyphenols from SCW such as the extraction solvent, time, solid-toliquid composition, temperature of the reaction mixture, etc. As per the authors best of their knowledge, no studies were carried out that incorporated SCW in a biorefinery concept to extract more than one value added products. Therefore, the objective of the study is to develop the organosolv process in compliance with the biorefinery concept. An RSM model was developed involving four parameters viz. solvent concentration, temperature, time and catalyst concentration to for efficient extraction of polyphenolic compounds from SCW. Subsequently, the pretreated SCW was subjected to enzymatic hydrolysis and increase in reducing sugar yield was analysed.

\section{Materials and methods}

The spent coffee waste (SCW) used throughout this project was obtained from a local coffee outlet in Dublin city. The SCW was dried at $80{ }^{\circ} \mathrm{C}$ for $48 \mathrm{~h}$ in and then stored at room temperature for further experiments. Other chemicals such as cellulase from Trichoderma reesei, hemicellulase from Aspergillus niger, conc. $\mathrm{H}_{2} \mathrm{SO}_{4}$ (HPLC Grade) and ethanol (HPLC Grade) were purchased from Sigma Aldrich, Ireland. From a previous study it was established that the activity of cellulase was $77 \mathrm{FPU} / \mathrm{ml}$. Meanwhile hemicellulase registered $72 \mathrm{U} / \mathrm{ml}$ activity (Ravindran et al., 2017a). The cellulase activity was measured by following protocol devised at the National Renewable Energy Laboratory, US (Adney and Baker, 1996). The hemicellulose activity was measured by following methods described by Rickard and Laughlin (1980).

\subsection{Characterisation of SCW}

\subsubsection{Moisture content}

The moisture content was determined as per the method described by Horwitz and Latimer (2000). Accordingly, $10 \mathrm{~g}$ of SCW was weighed into a glass beaker and placed in an oven set at $100 \pm 2{ }^{\circ} \mathrm{C}$ for $48 \mathrm{~h}$. The weight of the empty beaker, the wet sample and the dry sample were all recorded. The moisture content was determined using the following formula:

Moisture Content $(\%)=($ Wet sample - Dry sample $/$ Wet sample $) \times 100$

\subsection{Chemical composition of SCW}

The chemical composition of pretreated and native SCW was determined by following two stage acid hydrolysis according to the National Renewable Energy Laboratory (NREL) protocol (Sluiter et al., 2006). Briefly, $300 \mathrm{~g}$ of SCW was hydrolysed using $72 \% \mathrm{H}_{2} \mathrm{SO}_{4}$ at $30{ }^{\circ} \mathrm{C}$ for $60 \mathrm{~min}$. The mixture was then diluted to $4 \%$ by adding distilled water and autoclaved for $60 \mathrm{~min}$. The solids were separated from the liquids using a filtering crucible. The liquids were analysed for monosaccharides using Alliance HPLC (Waters, e2695 Separation module) using a Rezex ROA-Organic acid $\mathrm{H}+(8 \%)$ column, $(350 \times 7.8 \mathrm{~mm}$; Phenomenex, UK) with $5 \mathrm{mM} \mathrm{H}_{2} \mathrm{SO}_{4}$ as the mobile phase at $65^{\circ} \mathrm{C}$ maintaining a flow rate of $0.6 \mathrm{ml} / \mathrm{min}$ (Jaiswal et al., 2012a,b).

\subsection{Extraction of lipids}

Lipid extraction from SCW was done according protocol described by Ahangari and Sargolzaei (2013) with minor modifications. An empty round bottom flask with 2 anti-bumping granules were weighed. A cellulose thimble was filled with $10 \mathrm{~g}$ of dried SCW and stoppered using cotton wool. The weight of the SCW was recorded. The thimble was slotted into the Soxhlet chamber and $100 \mathrm{ml}$ of Petroleum ether was poured over it. The arrangement was kept on a heating mantle and heated. The cycle ran for $6 \mathrm{~h}$, allowing the Petroleum ether to reflux. The Petroleum ether was evaporated off, leaving behind only the oil sample. The flask was weighed again to record the weight after the lipid extraction. The oils were removed from the flask and stored in the fridge at $4{ }^{\circ} \mathrm{C}$. The total lipid content was calculated using the following formula:

Total Lipids $\%=($ Flask\&Oil - Empty flask $/$ SCW weight $) \times 100$

\subsection{Modified organosolv pretreatment and efficient extraction of polyphenols}

A response surface methodology design was applied to optimise an organosolv treatment using ethanol with the aim of achieving maximum polyphenol liberation (Goh et al., 2011). Ethanol and high temperature has been reported as influential factors in the efficient extraction of polyphenols from coffee waste products (Pavlović et al., 2013). Interestingly, Pan et al. (2003) reported the importance of maintaining acidic conditions for the effective extraction of polyphenols for green tea leaves. Additionally, sulphuric acid plays a vital role in the delignification of plant biomass in organosolv pretreatment (Zhao et al., 2009). Hence a design involving four factors viz. ethanol concentration, temperature, time and sulphuric acid concentration was devised. A central composite design (CCD) with four factors and four levels which also included five replicating centre points was devised using STATGRAPHICS Centurion XV software version 15.1.02 (StatPoint Technologies Inc. Warrenton, VA, USA) (Scully et al., 2016). The range of parameters was defined as follows: ethanol concentration $20 \%$ to $100 \%(\mathrm{v} / \mathrm{v})$, temperature $30{ }^{\circ} \mathrm{C}$ to $70{ }^{\circ} \mathrm{C}$, time $30 \mathrm{~min}$ to $60 \mathrm{~min}$ and sulphuric acid concentration $0.5 \%$ to $2 \%$ (Table 1 ). To perform each RSM experiment, $2.5 \mathrm{~g}$ of lipid free SCW was taken in a constant liquid volume of $22.5 \mathrm{ml}$ while maintaining the ethanol and $\mathrm{H} 2 \mathrm{SO} 4$

Table 1

Process variable and levels in CCD.

\begin{tabular}{|c|c|c|c|c|c|c|}
\hline \multirow[t]{2}{*}{ Independent variables } & \multirow[t]{2}{*}{ Coded symbols } & \multicolumn{5}{|c|}{ Levels } \\
\hline & & -2 & -1 & 0 & +1 & +2 \\
\hline Methanol conc. (\%) & $X_{1}$ & 20 & 40 & 60 & 80 & 100 \\
\hline Temperature $\left({ }^{\circ} \mathrm{C}\right)$ & $X_{2}$ & 30 & 40 & 50 & 60 & 70 \\
\hline Time (min) & $X_{3}$ & 15 & 30 & 45 & 60 & 75 \\
\hline Sulphuric acid conc. (\%) & $X_{4}$ & 0.5 & 1.0 & 1.5 & 2.0 & 2.5 \\
\hline
\end{tabular}


concentrations to the respective trial. The experiments were conducted at varying temperatures and for different time periods in accordance to the RSM design. On completion of the reaction, the solids were separated from the liquids by transferring the mixture into to $30 \mathrm{ml}$ polypropylene tubes and centrifuging at $7000 \mathrm{rpm}$ for $10 \mathrm{~min}$. The solid and liquid fractions were collected separately. The solids were dried at $65^{\circ} \mathrm{C}$ for $15 \mathrm{~h}$ and stored in a cool and dry place. The liquids were collected and subjected to further analysis. Furthermore, the main effects, quadratic effects and interaction effects were also studied during the process.

\subsection{Estimation of Total Polyphenol Content (TPC)}

Total Polyphenol Content (TPC) in the liquids obtained from the RSM experiments were estimated following protocols described by Shannon et al. (2018). $100 \mu \mathrm{l}$ sample was mixed with $2 \mathrm{ml}$ sodium carbonate and incubated at room temperature for $2 \mathrm{~min}$. To this mixture, $100 \mu \mathrm{l}$ Folin-Ciocalteu phenol reagent was then added and placed in the dark for $30 \mathrm{~min}$ at room temperature. Subsequently, the absorbance was measured at $720 \mathrm{~nm}$ and recorded. Gallic acid was used as standard.

\subsection{Estimation of Total Flavonoid Content (TFC)}

Total Flavonoid Content (TFC) was measured as follows: $250 \mu \mathrm{l}$ of the sample was diluted with $1.25 \mathrm{ml}$ of distilled $\mathrm{H}_{2} \mathrm{O}$ and then supplemented with $75 \mu \mathrm{l}$ of the $5 \% \mathrm{NaNO}_{2}$. The solution was incubated for $6 \mathrm{~min}$ at room temperature following which $500 \mu \mathrm{l}$ of $1 \mathrm{M} \mathrm{NaOH}$ was added and incubated further for 5 more minutes. The mixture was then made up to $2.5 \mathrm{ml}$ using distilled $\mathrm{H}_{2} \mathrm{O}$. The contents of the test tube were mixed thoroughly before the absorbance was measured against the blank at $510 \mathrm{~nm}$ (Shannon et al., 2018).

\subsection{Total antioxidant capacity of extracted polyphenols}

\subsubsection{DPPH radical scavenging activity}

The scavenging effects of the liquid obtained from the RSM experiments were estimated following protocols described by Shannon et al. (2018). Briefly, $100 \mu \mathrm{l}$ of $16 \mathrm{mM}$ DPPH (dissolved in methanol) was pipetted into a 96 well-plate. $100 \mu \mathrm{l}$ of the liquid obtained from the SCW organosolv treatments (diluted to 1:200) was pipetted in on top of the DPPH. After thorough mixing for $1 \mathrm{~min}$, the plate was incubated in the dark for $30 \mathrm{~min}$. Consequently, the absorbance was measured at $517 \mathrm{~nm}$ (Ganesan et al., 2008). Ascorbic acid was used to create standards.

\subsubsection{Ferric Reducing Antioxidant Power (FRAP)}

The antioxidant activity of the liquid obtained RSM validation experiments was also measured using FRAP assay and were estimated following protocols described by Mussatto et al. (2011). $10 \mu \mathrm{l}$ of the organosolv liquor was filtered and mixed with $290 \mu \mathrm{l}$ of FRAP reagent in a 96 well-microplate and incubated at $37^{\circ} \mathrm{C}$ for $15 \mathrm{~min}$. Subsequently, the absorbance was measured at $593 \mathrm{~nm}$. Distilled water was used as blank. A calibration curve was constructed using Tolox standards.

\subsection{Chemical characterisation of native and processed spent coffee waste}

\subsubsection{Scanning electron microscopy}

Dried samples of both untreated and pretreated SCW were subjected to FE-SEM. A Hitachi SU-70 Field emission microscope operating at electron beam energy of $0.5 \mathrm{keV}$ was employed for this purpose (Raghavi et al., 2016).

\subsubsection{X-ray diffraction}

Siemens D-500 X-ray diffractometer was employed for this purpose.
The diffraction angles were spanned from $2 \theta=5^{\circ}-50^{\circ}$. The radiation was generated at a voltage of $40 \mathrm{kV}$, current of $30 \mathrm{~mA}$ by $\mathrm{Cu} \mathrm{Ka}$ radiation source $(\lambda=0.154 \mathrm{~nm})$.

\subsubsection{FTIR analysis}

Perkin Elmer Spectrum GX FT-IR (UATR) Microscope (USA) was employed to obtain FTIR spectra of spent coffee waste. The spectra were recorded from 4000 to $400 \mathrm{~cm}^{-1}$ with 32 scans at a resolution of $0.3 \mathrm{~cm}^{-1}$ in transmission mode.

\subsubsection{Thermal analysis}

The variations in thermal behaviour in the pretreated SCW at the backdrop of native SCW was analysed using Differential Scanning Calorimetry (DSC). A Shimadzu Differential Scanning Calorimeter DSC60 installed with TA-60WS software was employed for this purpose. Each SCW sample $(55 \mathrm{mg}$ ) was taken in an aluminium pan with an empty pan used as a reference. All measurements were carried out between $25^{\circ} \mathrm{C}$ and $500{ }^{\circ} \mathrm{C}$ maintaining a linear increase of $10^{\circ} \mathrm{C} / \mathrm{min}$.

\subsection{Enzymatic hydrolysis}

Enzymatic hydrolysis was of the pretreated SCW carried out following optimised parameters devised by Scully et al. (2016). Briefly, $5.0 \mathrm{~g}$ of solid residue from the optimised organosolv treatment was weighed and mixed with $42.79 \mathrm{ml}$ distilled $\mathrm{H}_{2} \mathrm{O}$ was added in followed by $5 \mathrm{ml}$ of a $4.8 \mathrm{pH}$ buffer (stock of $500 \mathrm{~mm}$ ). Cellulase and hemicellulase enzymes were then added in at $1.46 \mathrm{ml}$ (112.42 FPU) and $0.250 \mathrm{ml}(18 \mathrm{U} / \mathrm{ml})$, respectively. Finally, to prevent any microbial contamination, $0.5 \mathrm{ml}$ sodium azide was added to achieve a desired concentration of $0.02 \%$ in the end reaction mixture maintaining a total volume of $50 \mathrm{ml}$. The reaction mixture was incubated at $50^{\circ} \mathrm{C}$ for $120 \mathrm{~h}$ at $100 \mathrm{rpm}$. Upon completion of the enzymatic hydrolysis, the solids were separated from the liquids. The reducing sugar content in the liquor was analysed by DNS method (Miller, 1959). Additionally, the monosaccharides and the incidence of any inhibitory compounds such as furfural and hydroxy methyl furfural or organic acids were analysed using HPLC following protocol devised by Ravindran et al. (2017a).

\section{Results and discussion}

Solvent concentration, temperature, pretreatment time and the presence or absence of a catalyst are four important factors that influence the efficiency of the organosolv pretreatment process. Several researchers in separate studies have reported on the extraction of antioxidants from SCW as well as the utilisation of the same for fermentable sugar and second-generation biofuel production (Jooste et al., 2013; Kwon et al., 2013; Panusa et al., 2013). This study was an attempt to combine established technologies to increase the value addition in during valorisation of SCW.

\subsection{Composition analysis of SCW}

SCW is mainly composed of carbohydrates and lignin. The carbohydrate fraction of SCW constitutes of polymerised sugars in the form of cellulose and hemicellulose. While cellulose is a homopolymer of repeating glucose units, hemicellulose is mainly composed of galactose, mannose and arabinose. Xylose was not found in SCW. The compositional analysis of SCW revealed that it is composed mainly of hemicellulose content which amounted to $33.5 \pm 0.5 \mathrm{~g}$ per $100 \mathrm{~g}$ of SCW. This number for cellulose was as low as $8.6 \mathrm{~g} \pm 0.1 / 100 \mathrm{~g}$ of SCW. With a high hemicellulose content, it can be safely concluded that SCW is rich in galactomannan and glucomannan. The total lignin content in SCW amounted up to $23.15 \pm 0.4 \mathrm{~g}$ per $100 \mathrm{~g}$ of SCW of which the insoluble fraction was found to be $17.50 \pm 0.6 \mathrm{~g} / 100 \mathrm{~g} \mathrm{SCW}$ and the soluble portion contributed to $5.65 \pm 0.4 \mathrm{~g} / 100 \mathrm{~g}$ SCW. A small fraction of the total weight of SCW was contributed by its lipid content. 
According to our study, $13.4 \%$ of the total SCW weight was contributed by its lipid content. This number can vary within the range of $10-20 \%$ based on the variety of the coffee bean, the solvent used, and reflux times set for lipid extraction. Akgün et al. (2014) had reported that the lipid content in SCW fell within the range of 12.29-14.88\%. Moisture content contributed to $60 \%$ total weight of fresh SCW. Corrêa et al. (2014) reported that the moisture content in spent coffee grounds to be $56.7 \%$.

\subsection{Optimisation of organosolv pretreatment using response surface methodology}

The aim of the RSM optimisation experiment was to maximise antioxidant polyphenol recovery through the organosolv pretreatment process of SCW. Solvent concentration was expected to be the most important parameter in the extraction of polyphenols. The polynomial equation for the model is as follows:

Total Polyphenol Content $(\mathrm{GAE} / \mathrm{g})=-2961.13+54.4251 X_{1}+57.7705 X_{2}$

$$
\begin{aligned}
& +31.1713 X_{3}+44.9172 X_{4}-0.430616 X_{1}^{2} \\
& -0.00899062 X_{1} X_{2}-0.0817396 X_{1} X_{3} \\
& +5.37319 X_{1} X_{4}-0.644776 X_{2}^{2} \\
& +0.082908 X_{2} X_{3}+3.43788 X_{2} X_{3} \\
& -0.384317 X_{3}^{2}+2.97675 X_{3} X_{4} \\
& -230.886 X_{4}^{2}
\end{aligned}
$$

where $X_{1}, X_{2}, X_{3}$, and $X_{4}$ represent methanol concentration, temperature, time and sulphuric acid concentration respectively. Table 2 represents the results obtained after conducting the CCD experiments which contains data for studying the effects of four independent variables. Data were fitted into a first order polynomial equation mentioned above and good agreement was observed between the experimental data with the data predicted by the model. The coefficient $\mathrm{R}^{2}$ represents the magnitude of variation of fitted data from that predicted by the model. A high $\mathrm{R}^{2}$ value guarantees the validity of the model and its
Table 3

Analysis of variance obtained for total phenolic content recovery.

\begin{tabular}{llllll}
\hline Source & Sum of squares & Df* & Mean square & F-ratio & P-value \\
\hline A & 428,779 & 1 & 428,779 & 40.59 & 0.0000 \\
B & 6468.5 & 1 & 6468.5 & 0.61 & 0.4470 \\
C & 452.836 & 1 & 452.836 & 0.04 & 0.8390 \\
D & 2281.7 & 1 & 2281.7 & 0.22 & 0.6493 \\
AA & 769,786 & 1 & 769,786 & 72.86 & 0.0000 \\
AB & 51.7321 & 1 & 51.7321 & 0.00 & 0.9452 \\
AC & 9621.16 & 1 & 9621.16 & 0.91 & 0.3561 \\
AD & $46,193.8$ & 1 & $46,193.8$ & 4.37 & 0.0552 \\
BB & 107,867 & 1 & 107,867 & 10.21 & 0.0065 \\
BC & 2475.31 & 1 & 2475.31 & 0.23 & 0.6358 \\
BD & 4727.59 & 1 & 4727.59 & 0.45 & 0.5144 \\
CC & 194,006 & 1 & 194,006 & 18.36 & 0.0008 \\
CD & 7974.94 & 1 & 7974.94 & 0.75 & 0.3996 \\
DD & $86,445.7$ & 1 & $86,445.7$ & 8.18 & 0.0126 \\
Total error & 147,907 & 14 & $10,564.8$ & & \\
Total (corr.) & $1.52488 \mathrm{E} 6$ & 28 & & & \\
\end{tabular}

* Df: degrees of freedom.

applicability for the chosen variables in this study. An $\mathrm{R}^{2}$ value of $>75 \%$ is found to be suitable for most optimisation experiments. The adjusted $\mathrm{R}^{2}$ value in this study was found to be $80.60 \%$ thus deeming the model valid.

Table 3 represents the analysis of variance of the experiments and indicated that the linear model terms $X_{2}, X_{3}$ and $X_{4}$ had a negative effect on total polyphenol extraction $(\mathrm{P}<0.05)$. This may be due to the negative influence of increasing temperature, time and acid concentration on the total polyphenol yield. Table 2 also provides insights on the interactive effects of factors used in this study on TPC. No interactions between two factors were found to be significant enough to affect the TPC yield $(\mathrm{P}<0.05)$. An $\mathrm{R}^{2}$ value of $90.3 \%$ was achieved from the data. This means that the variables tested account for only

\begin{tabular}{|c|c|c|c|c|c|c|}
\hline Run no. & Ethanol conc. (\%) & Temperature $\left({ }^{\circ} \mathrm{C}\right)$ & Time (min) & $\mathrm{H}_{2} \mathrm{SO}_{4}$ conc. (\%) & Observed yield (GAE/g) & Theoretical yield (GAE/g) \\
\hline 1 & 40.0 & 60.0 & 60.0 & 1.0 & 584.29 & 653.262 \\
\hline 2 & 40.0 & 60.0 & 60.0 & 2.0 & 577.43 & 605.328 \\
\hline 3 & 60.0 & 50.0 & 45.0 & 1.5 & 1103.5 & 1084.36 \\
\hline 4 & 80.0 & 60.0 & 60.0 & 1.0 & 798.86 & 760.485 \\
\hline 5 & 80.0 & 40.0 & 30.0 & 2.0 & 837.43 & 859.566 \\
\hline 6 & 80.0 & 60.0 & 30.0 & 1.0 & 843.86 & 820.616 \\
\hline 7 & 20.0 & 50.0 & 45.0 & 1.5 & 324.57 & 128.045 \\
\hline 8 & 60.0 & 30.0 & 45.0 & 1.5 & 849.57 & 793.611 \\
\hline 9 & 60.0 & 50.0 & 45.0 & 1.5 & 1095.52 & 1084.36 \\
\hline 10 & 60.0 & 50.0 & 45.0 & 2.5 & 990.29 & 833.97 \\
\hline 11 & 60.0 & 50.0 & 75.0 & 1.5 & 773.62 & 747.158 \\
\hline 12 & 80.0 & 40.0 & 60.0 & 1.0 & 806.0 & 740.749 \\
\hline 13 & 60.0 & 50.0 & 45.0 & 0.5 & 823.62 & 872.971 \\
\hline 14 & 80.0 & 60.0 & 30.0 & 2.0 & 894.21 & 898.306 \\
\hline 15 & 80.0 & 40.0 & 60.0 & 2.0 & 817.43 & 838.985 \\
\hline 16 & 80.0 & 60.0 & 60.0 & 2.0 & 908.5 & 927.477 \\
\hline 17 & 40.0 & 40.0 & 60.0 & 2.0 & 395.29 & 509.642 \\
\hline 18 & 40.0 & 40.0 & 60.0 & 1.0 & 614.57 & 626.335 \\
\hline 19 & 40.0 & 40.0 & 30.0 & 2.0 & 377.9 & 432.136 \\
\hline 20 & 40.0 & 60.0 & 30.0 & 2.0 & 321.71 & 478.069 \\
\hline 21 & 60.0 & 50.0 & 45.0 & 1.5 & 1058.14 & 1084.36 \\
\hline 22 & 60.0 & 50.0 & 15.0 & 1.5 & 810.29 & 729.783 \\
\hline 23 & 60.0 & 70.0 & 45.0 & 1.5 & 910.29 & 859.28 \\
\hline 24 & 40.0 & 40.0 & 30.0 & 1.0 & 566.0 & 638.131 \\
\hline 25 & 40.0 & 60.0 & 30.0 & 1.0 & 621.0 & 615.306 \\
\hline 26 & 80.0 & 40.0 & 30.0 & 1.0 & 862.67 & 850.633 \\
\hline 27 & 60.0 & 50.0 & 45.0 & 1.5 & 1058.14 & 1084.36 \\
\hline 28 & 60.0 & 50.0 & 45.0 & 1.5 & 1106.48 & 1084.36 \\
\hline 29 & 100.0 & 50.0 & 45.0 & 1.5 & 573.14 & 662.696 \\
\hline
\end{tabular}
$90 \%$ of the variability in the TPC results inferring that the four factors and their combinations did not account for all the variability present in this study and an unknown factor may also have influenced the

Table 2

CCD experimental designs for five independent variables, experimental and predicted values for total phenolic content yield. 

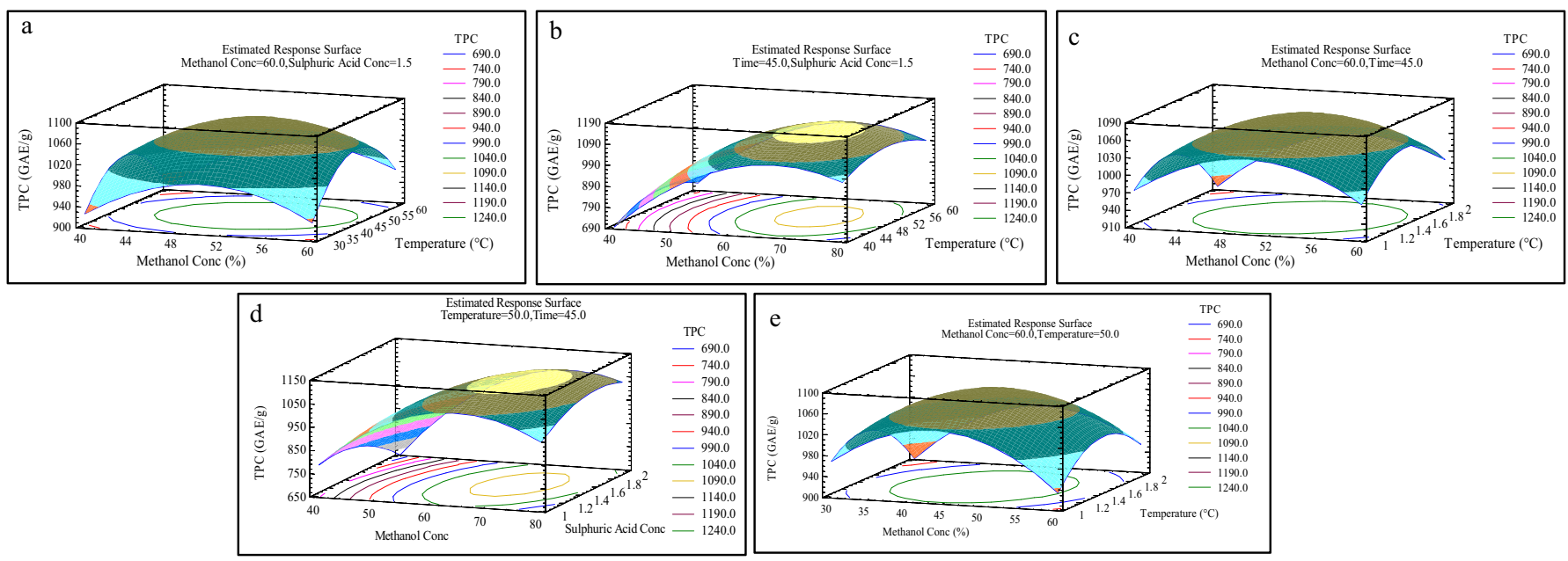

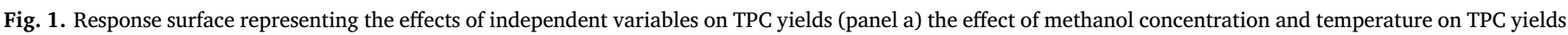

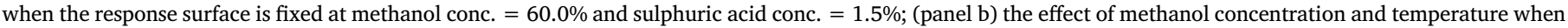

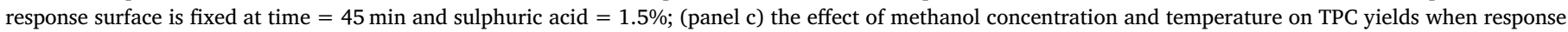

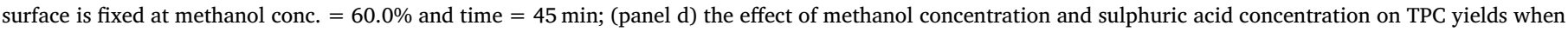

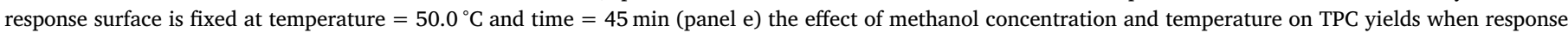
surface is fixed at methanol conc. $=60.0 \%$ and temperature $=50{ }^{\circ} \mathrm{C}$.

\section{outcome.}

Graphical 3-D response plots (Fig. 1) provide a detailed understanding of the predicted TPC yield (GAE/g) by the final quadratic equation and the values obtained after each experimental trial. 3-D response plots are graphical representations of the quadratic equation. They provide an understanding of the interactions between different variables. Analysing these plots gives on the idea about the optimal level for each variable to maximise the response. Response surface plots are plotted as a combination of two variables while the third parameter is kept constant at the centre point. Symmetrical surfaces with flat regions near the optimum are indications of optimised values being stable over single variable conditions. The extent of significant interactions between each factor determines the number of lines, curvature and the degree of curl of the contour plots. Three-dimensional contour plots generated gave acumen on the interactions between the four factors considered in this study. As was with the Pareto chart the influential effect of ethanol concentration alone was evident in the graphical response plots.

\subsection{Testing of the optimised conditions}

Based on the RSM study organosolv process was modified to use $68 \%$ ethanol concentration, at $51.4^{\circ} \mathrm{C}$ for $45 \mathrm{~min}$ using an acid concentration of $1.5 \%$ to extract maximum TPC from SCW while still be competent as a pretreatment method for reducing the sugar release. The TPC yield obtained by applying these conditions for extraction was found to be $11.12 \mathrm{mg} \mathrm{GAE} / \mathrm{g}$ of SCW.

\subsection{Identification and quantification of reducing sugars and monosaccharides}

The effects of modified organosolv pretreatment on the reducing sugar release were investigated by enzymatic hydrolysis of the dry, pretreated SCW. DNS assay of the hydrolysate revealed the reducing sugar content to be $29.05 \mathrm{mg} / \mathrm{g}$ of SCW. This was 1.27 times higher than the reducing sugar yield obtained from hydrolysis of native SCW $(22.81 \mathrm{mg} / \mathrm{g})$. This indicated that the modified organosolv process was successful in the removal of recalcitrance in SCW thereby allowing the cellulytic enzymes enhanced accessibility to the polysaccharide fraction. For further analysis, the hydrolysate was subjected to HPLC analysis to identify and quantify the monosaccharides present. Four major sugars were identified in the hydrolysate viz. glucose, galactose, arabinose and mannose. Xylose was absent in the hydrolysate. This fact has been reported in several other studies as well (Ballesteros et al., 2015; Ravindran et al., 2017a). Furthermore, no inhibitory compounds such as furfural and hydroxy methyl furfural were identified in the pretreatment liquor, which was a positive factor in the modified organosolv process. This may be due to the absence of high temperatures that is required for the formation of the aforementioned inhibitory compounds from lignocellulose component fractions.

\subsection{Total Polyphenol Content and antioxidant activity}

The modified organosolv process did have a positive influence on the polyphenol yield from SCW (Table 4). However, this value was comparatively lesser than those reported by Mussatto et al. (2011) (16.0 mg GAE per $\mathrm{g}$ of SCW) and Zuorro (2015) (24.25 mg GAE/g of SCW). Studies have reported that a large proportion of this is condensed tannins as it has been documented that tannins make up 4\% of SCW (Pujol et al., 2013). Additionally, this variation between literature and actual yield can be owed to the variety of coffee bean, the type of pretreatment applied or even more importantly the type of brewing process applied. Total Flavonoid Content assay was executed and retrieved an average result of 13.78 of QE/g of dry SCW. This was high compared to the control experiment ( $1.81 \mathrm{mg}$ QE/g SCG). Pretreatment essentially disrupts the complex structures within lignocellulosic materials resulting in the release of the polyphenol fraction (Scully et al., 2016). The antioxidant activity of the pretreated and native SCW was measured by DPPH free radical scavenging activity and FRAP assay. The DPPH free radical scavenging assay revealed that the antioxidant activity results revealed a value of $11.31 \mathrm{mg}$ of AAE (ascorbic acid equivalents). Meanwhile the FRAP assay gave rise to an antioxidant activity of $10 \mathrm{mg}$ TE per $\mathrm{g}$ of SCW. The difference in values of antioxidant activities measured by both assays may be due the differences in electron transfer mechanisms in assays. FRAP assay the antioxidants

Table 4

Summary of polyphenol and antioxidant capacity of SCW.

\begin{tabular}{llll}
\hline TPC (mg GAE $/ \mathrm{g})$ & TFC (mg QE $/ \mathrm{g})$ & DPPH $(\mathrm{mg} \mathrm{AAE} / \mathrm{g})$ & FRAP $(\mathrm{mg} \mathrm{TE} / \mathrm{g})$ \\
\hline $10.00 \pm 1.23$ & $13.78 \pm 0.07$ & $11.31 \pm 1.80$ & $10.00 \pm 1.40$ \\
\hline
\end{tabular}


capable of making a single electron transfer. On the other hand, DPPH assay measures both single electron transfers and the transfer of hydrogen atoms. This makes both assays reaching a consensus difficult (Prior et al., 2005).

\subsection{Effect of modified organosolv pretreatment on SCW composition}

Organosolv pretreatment in this utilised ethanol as the organic solvent for lignin removal. This strategy is generally a very effective technique in eliminating recalcitrance in lignocellulose and complies with biorefinery concept since the lignin removed can be regained through distillation. Furthermore, solvent used can be recycled and used again in the process. Organosolv pretreatment is normally conducted in a temperature range of $150{ }^{\circ} \mathrm{C}$ to $180^{\circ} \mathrm{C}$ (Amiri et al., 2014). Modifications were made to the organosolv process in this study to maximise polyphenol recovery which resulted in conducting the process in lower temperatures $\left(51{ }^{\circ} \mathrm{C}\right)$. Therefore, the pretreatment was not as effective as the conventional organosolv process in terms of lignin removal. As mentioned earlier, the lignin content in SCW was found to be $23.15 \pm 0.6 \mathrm{~g} / 100 \mathrm{~g}$ of SCW. After pretreatment this fraction reduced to $18.76 \pm 0.3 \mathrm{~g} / 100 \mathrm{~g}$ of SCW. The total hemicellulose content in pretreated SCW was found to be $27.23 \mathrm{~g} \pm 0.7 / 100 \mathrm{~g}$ of SCW conserving $81.3 \%$ of the original hemicellulose content. However, the cellulose content was found to be $6.28 \mathrm{~g} / 100 \mathrm{~g}$ of SCW conserving only $77.9 \%$ of the original SCW content. Nonetheless, a high reducing sugar yield of $29.05 \pm 0.5 \mathrm{mg} / \mathrm{g}$ of SCW was obtained when subjecting pretreated biomass to enzymatic hydrolysis. This was 1.27 -fold more than reducing sugar obtained when native SCW was subjected to enzymatic hydrolysis $(22.8 \pm 0.4 \mathrm{mg} / \mathrm{g}$ of SCW $)$. The increase in reducing sugar content was due to the extensive lignin degradation which resulted in a greater access of lignocellulolytic enzymes towards the polysaccharide fraction of SCW. Furthermore, the efficient removal of polyphenols from SCW will also have contributed to higher hydrolysis and subsequent reducing sugar yield. Similar observations were reported by He et al. (2007) where the presence of polyphenols can decrease the activity of different digestive enzymes such as $\alpha$-amylase by $61 \%$. On subjecting to HPLC analysis the hydrolysate was found to be high in hemicellulose sugars such as mannose $(5.67 \mathrm{mg} / \mathrm{ml})$, arabinose $(7.13 \mathrm{mg} / \mathrm{ml})$, cellobiose $(2.13 \mathrm{mg} / \mathrm{ml})$ and galactose $(4.51 \mathrm{mg} / \mathrm{ml})$. The glucose content in the hydrolysate was found to be $1.69 \mathrm{mg} / \mathrm{ml}$. It may be safely assumed that the majority of reducing sugars were contributed by hemicellulose.

\subsection{SEM, XRD, DSC and FTIR profiles of untreated and pre-treated spent coffee waste}

SEM analysis was conducted to determine the structural and morphological changes brought about by the pretreatment on the surface of SCW. Native SCW was found to be very porous in nature. SCW was found to be highly porous, non-fibrous and sheet like in nature. Results showed that the major effects brought about by modified organosolv pretreatment, and a stark reduction in particle size was observed. This may be due to the disruption of component structures brought about in SCW by the pretreatment. Lignin fractions along with polyphenols contribute to structural integrity of SCW. Removal of these components may have resulted in structural disintegration. The reduction in particle size will have contributed to increased overall surface area thus increasing the efficiency of enzymatic hydrolysis thus resulting in higher reducing sugar yield.

Crystallinity in lignocellulosic biomass is majorly contributed by the presence of cellulose. Cellulose can be crystalline and amorphous in nature. Crystalline cellulose resists digestion by enzymatic hydrolysis while its amorphous counterpart can be easily converted into component sugars. For these reasons, the study of crystallinity of pretreated and native SCW was empirical in understanding the changes in composition brought about by modified organosolv pretreatment.
Subsequently this analysis also revealed the effectiveness of enzymatic hydrolysis. In a typical XRD spectrum peaks at $15^{\circ}$ and $22^{\circ}$ represent the amorphous and crystalline fractions of lignocellulose respectively. Besides amorphous cellulose, hemicellulose and lignin components contribute to the amorphous nature of lignocellulosic biomass. In the XRD spectra of native SCW and its pretreated counterpart, distinct peaks for amorphous and crystalline regions were not observed. Similar observations were reported by Ballesteros et al. (2015) where an extensive study was conducted to characterise the various properties of spent coffee waste and coffee sliver. SCW subjected to modified organosolv pretreatment was found to be amorphous in nature. From the compositional analysis it was evident that there was loss in cellulose content which may have led to loss in crystallinity. This may be attributed to the decrease in cellulose content coupled with the increase in hemicellulose content. Similar observations were reported by Sannigrahi et al. (2010) when a study was conducted in which loblolly pine was subjected to organosolv pretreatment. Furthermore, Xu et al. (2012) had reported the negative effect of hemicellulose content on lignocellulose crystallinity.

FTIR analysis was conducted to determine the various changes in functional groups brought about by the modified organosolv pretreatment in SCW. The FTIR spectrum showed that the changes in $\beta$-glycosidic linkages that exist between cellulose and hemicellulose are represented by bands at $897 \mathrm{~cm}^{-1}$. A change in this band would translate into the stretching or breakage of this linkage between cellulose and hemicellulose as well as the intermolecular disruption in cellulose structure. There was a decrease in absorbance of the band in pretreated SCW compared to native SCW representing severing of $\beta$-glycosidic bonds. The $\mathrm{C}-\mathrm{C}$ and $\mathrm{C}-\mathrm{C}-\mathrm{O}$ bonds are represented by $1035 \mathrm{~cm}^{-1}$ and is indicative of the bond that exist between the carbohydrate and lignin fractions. A decrease in the absorbance at this wavenumber was observed signifying bond stretching. The decrease of absorbance at $1200 \mathrm{~cm}^{-1}$ is attributed by the breaking of hydrogen bonds between cellulose and hemicellulose. Any changes in the absorbance at band $1509 \mathrm{~cm}^{-1}$ are due to the changes in lignin content. The bands at $1730 \mathrm{~cm}^{-1}$ and $1750 \mathrm{~cm}^{-1}$ represent the ester moieties in hemicellulose and in turn the strong presence of the polysaccharide. The broadening of peaks at $3000-3500 \mathrm{~cm}^{-1}$ is indicative of OH-stretching. Similar findings were observed in an earlier study conducted in our lab using coffee waste (Ravindran et al., 2017b).

Lignocellulose pellets are used as solid fuel sources as a means of renewable energy. Several studies have been focused on the thermal behaviour as well as the decomposition patterns of different types of lignocellulosic feedstock (Garcia-Maraver et al., 2013). In thermal decomposition processes of lignocellulose, lignin plays a key role in the formation of char. This has a direct impact on the secondary decomposition of lignocellulose in an oxidative environment (Sivasangar et al., 2013). Thus, it was important to study the thermal behaviour of the pretreated SCW at the backdrop of its native counterpart. Differential Scanning Calorimetry (DSC) is a thermal analytical technique that uses heat to study the polymeric nature of a solid substance. It used to understand the physical and chemical transitions associated with heat effects as a function of temperature. A typical thermogram obtained from a DSC study will contain five events: a starting transient, glass transition, crystallisation, melting and ending transient. Fig. 2 represents the changes brought in the thermal behaviour of SCW about modified organosolv pretreatment. A temperature range of $20^{\circ} \mathrm{C}$ to $500{ }^{\circ} \mathrm{C}$ was selected for this purpose. The thermograms for both pretreated and native SCW was obtained by ramping up the temperature at a rate of $10{ }^{\circ} \mathrm{C}$ per minute under constant nitrogen atmosphere. Changes in the polymeric nature of SCW brought about by the pretreatment can be observed in the thermogram. Both the pretreated and native SCW start off with an exothermic event from $20^{\circ} \mathrm{C}$. However, the event pertaining to the pretreated SCW was short lived. Such an exothermic event occurs to the crystallinity as well as the vaporisation of water in the sample. This was followed by a glass transition event. As can be 


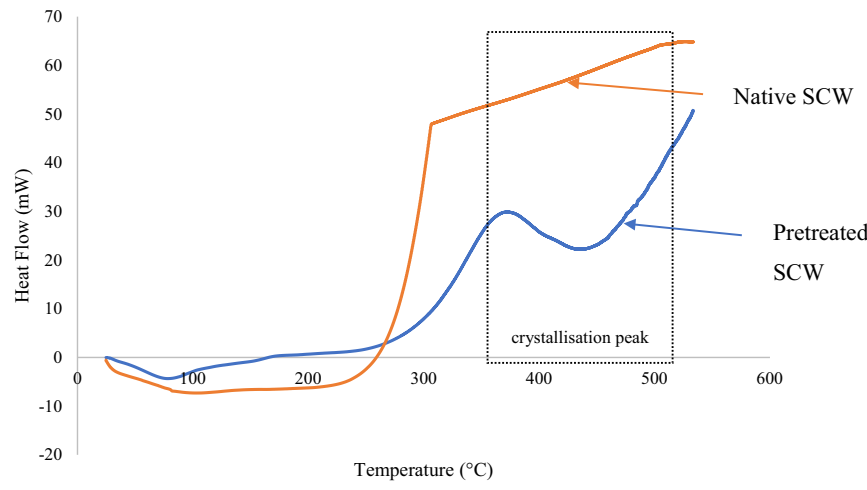

Fig. 2. DSC thermogram of pretreated and native SCW.

observed from figure, the native SCW entered glass transition much before the pretreated SCW. On the other hand, as soon as the pretreated SCW entered glass transition phase a crystallisation peak was observed which was marked between temperatures $370{ }^{\circ} \mathrm{C}$ and $500{ }^{\circ} \mathrm{C}$. No such crystallisation peak was observed in the thermogram of native SCW. Peak changes can be attributed to the change in composition of SCW in particular, the hemicellulose and lignin content. The shift in peak from $280^{\circ} \mathrm{C}$ to $190^{\circ} \mathrm{C}$ can be due to the decrease in cellulose and lignin content. Similar observations were reported by Ravindran et al. (2017b) when SCW was subjected to organosolv pretreatments involving higher temperatures.

\section{Conclusion}

SCW is a huge reservoir of polyphenols, flavonoids and polysaccharides. Therefore, an innovative technology was successfully developed to extract maximum polyphenols while achieving lignin removal thus facilitating enhanced hydrolysis of SCW. Optimised organosolv pretreatment of SCW with ethanol $(68 \% \mathrm{v} / \mathrm{v})$ at $51{ }^{\circ} \mathrm{C}$ for $45 \mathrm{~min}$ in the presence of $1.5 \% \mathrm{H}_{2} \mathrm{SO}_{4}$ as catalyst resulted in achieving a total phenolic content yield of $11.2 \mathrm{mg} \mathrm{GAE} / \mathrm{g}$ of SCW, $24.4 \%$ lignin removal and a maximum reducing sugar yield of $29.05 \mathrm{mg} / \mathrm{g}$ of SCW (1.27-fold higher than native SCW). This pretreatment can be beneficially scaled up for biorefinery purposes.

\section{Acknowledgement}

The authors would like to acknowledge the funding from Dublin Institute of Technology (DIT), Ireland under the Fiosraigh Scholarship programme, 2014.

\section{Appendix A. Supplementary data}

Supplementary data to this article can be found online at https:// doi.org/10.1016/j.biteb.2018.05.009.

\section{References}

Adney, B., Baker, J., 1996. Measurement of cellulase activities. Lab. Anal. Proced. 6, 1996.

Ahangari, B., Sargolzaei, J., 2013. Extraction of lipids from spent coffee grounds using organic solvents and supercritical carbon dioxide. J. Food Process. Preserv. 37 (5), 1014-1021.

Akgün, N.A., Bulut, H., Kikic, I., Solinas, D., 2014. Extraction behavior of lipids obtained from spent coffee grounds using supercritical carbon dioxide. Chem. Eng. Technol. 37 (11), 1975-1981.

Amiri, H., Karimi, K., Zilouei, H., 2014. Organosolv pretreatment of rice straw for efficient acetone, butanol, and ethanol production. Bioresour. Technol. 152, 450-456.

Araque, E., Parra, C., Freer, J., Contreras, D., Rodríguez, J., Mendonça, R., Baeza, J., 2008. Evaluation of organosolv pretreatment for the conversion of Pinus radiata D. Don to ethanol. Enzym. Microb. Technol. 43 (2), 214-219.

Ballesteros, L.F., Cerqueira, M.A., Teixeira, J.A., Mussatto, S.I., 2015. Characterization of polysaccharides extracted from spent coffee grounds by alkali pretreatment.
Carbohydr. Polym. 127, 347-354.

Campos-Vega, R., Loarca-Piña, G., Vergara-Castañeda, H.A., Oomah, B.D., 2015. Spent coffee grounds: a review on current research and future prospects. Trends Food Sci. Technol. 45 (1), 24-36.

Corrêa, J.L.G., Santos, J.C.P., Fonseca, B.E., Carvalho, A.G.D.S., 2014. Drying of spent coffee grounds in a cyclonic dryer. Coffee Sci. 9 (1), 68-76.

Cruz, R., Cardoso, M.M., Fernandes, L., Oliveira, M., Mendes, E., Baptista, P., Morais, S., Casal, S., 2012. Espresso coffee residues: a valuable source of unextracted compounds. J. Agric. Food Chem. 60 (32), 7777-7784.

Ganesan, P., Kumar, C.S., Bhaskar, N., 2008. Antioxidant properties of methanol extract and its solvent fractions obtained from selected Indian red seaweeds. Bioresour. Technol. 99 (8), 2717-2723.

Garcia-Maraver, A., Salvachúa, D., Martínez, M.J., Diaz, L.F., Zamorano, M., 2013. Analysis of the relation between the cellulose, hemicellulose and lignin content and the thermal behavior of residual biomass from olive trees. Waste Manag. 33 (11), 2245-2249.

Go, A.W., Conag, A.T., Cuizon, D.E.S., 2016. Recovery of sugars and lipids from spent coffee grounds: a new approach. Waste Biomass Valoriz. 7 (5), 1047-1053.

Goh, C.S., Tan, H.T., Lee, K.T., Brosse, N., 2011. Evaluation and optimization of organosolv pretreatment using combined severity factors and response surface methodology. Biomass Bioenergy 35 (9), 4025-4033.

He, Q., Lv, Y., Yao, K., 2007. Effects of tea polyphenols on the activities of $\alpha$-amylase pepsin, trypsin and lipase. Food Chem. 101 (3), 1178-1182.

Horwitz, W., Latimer, G., 2000. Official Methods of Analysis of AOAC International, Gaithersburg MA, USA. Association of Official Analytical chemist.

Jaiswal, A.K., Abu-Ghannam, N., Gupta, S., 2012a. A comparative study on the polyphenolic content, antibacterial activity and antioxidant capacity of different solvent extracts of Brassica oleracea vegetables. Int. J. Food Sci. Technol. 47 (2), 223-231.

Jaiswal, A.K., Gupta, S., Abu-Ghannam, N., 2012b. Optimisation of lactic acid fermentation of York cabbage for the development of potential probiotic products. Int. J. Food Sci. Technol. 47 (8), 1605-1612.

Jönsson, L.J., Martín, C., 2016. Pretreatment of lignocellulose: formation of inhibitory byproducts and strategies for minimizing their effects. Bioresour. Technol. 199, 103-112.

Jooste, T., García-Aparicio, M., Brienzo, M., Van Zyl, W., Görgens, J., 2013. Enzymatic hydrolysis of spent coffee ground. Appl. Biochem. Biotechnol. 169 (8), 2248-2262.

Kwon, E.E., Yi, H., Jeon, Y.J., 2013. Sequential co-production of biodiesel and bioethanol with spent coffee grounds. Bioresour. Technol. 136, 475-480.

Ma, L., Cui, Y., Cai, R., Liu, X., Zhang, C., Xiao, D., 2015. Optimization and evaluation of alkaline potassium permanganate pretreatment of corncob. Bioresour. Technol. 180, 1-6.

Miller, G.L., 1959. Use of dinitrosalicylic acid reagent tor determination oi reducing sugar. Anal. Chem. 31 (3), 426-428.

Mohan, S.V., Nikhil, G.N., Chiranjeevi, P., Reddy, C.N., Rohit, M.V., Kumar, A.N., Sarkar, O., 2016. Waste biorefinery models towards sustainable circular bioeconomy: critical review and future perspectives. Bioresour. Technol. 215, 2-12.

Montoya, S., Orrego, C.E., Levin, L., 2012. Growth, fruiting and lignocellulolytic enzyme production by the edible mushroom Grifola frondosa (maitake). World J. Microbiol. Biotechnol. 28 (4), 1533-1541.

Mussatto, S.I., Ballesteros, L.F., Martins, S., Teixeira, J.A., 2011. Extraction of antioxidan phenolic compounds from spent coffee grounds. Sep. Purif. Technol. 83, 173-179.

Pan, X., Niu, G., Liu, H., 2003. Microwave-assisted extraction of tea polyphenols and tea caffeine from green tea leaves. Chem. Eng. Process. Process Intensif. 42 (2), 129-133.

Panusa, A., Zuorro, A., Lavecchia, R., Marrosu, G., Petrucci, R., 2013. Recovery of natura antioxidants from spent coffee grounds. J. Agric. Food Chem. 61 (17), 4162-4168.

Pavlović, M.D., Buntić, A.V., Šiler-Marinković, S.S., Dimitrijević-Branković, S.I., 2013. Ethanol influenced fast microwave-assisted extraction for natural antioxidants obtaining from spent filter coffee. Sep. Purif. Technol. 118, 503-510.

Prior, R.L., Wu, X., Schaich, K., 2005. Standardized methods for the determination of antioxidant capacity and phenolics in foods and dietary supplements. J. Agric. Food Chem. 53 (10), 4290-4302.

Pujol, D., Liu, C., Gominho, J., Olivella, M.À., Fiol, N., Villaescusa, I., Pereira, H., 2013. The chemical composition of exhausted coffee waste. Ind. Crop. Prod. 50, 423-429.

Raghavi, S., Sindhu, R., Binod, P., Gnansounou, E., Pandey, A., 2016. Development of a novel sequential pretreatment strategy for the production of bioethanol from sugarcane trash. Bioresour. Technol. 199, 202-210.

Ravindran, R., Jaiswal, A.K., 2016. Exploitation of food industry waste for high-value products. Trends Biotechnol. 34 (1), 58-69.

Ravindran, R., Jaiswal, S., Abu-Ghannam, N., Jaiswal, A.K., 2017a. Evaluation of ultrasound assisted potassium permanganate pre-treatment of spent coffee waste. Bioresour. Technol. 224, 680-687.

Ravindran, R., Jaiswal, S., Abu-Ghannam, N., Jaiswal, A.K., 2017b. Two-step sequentia pretreatment for the enhanced enzymatic hydrolysis of coffee spent waste. Bioresour. Technol. 239, 276-284.

Rickard, P., Laughlin, T., 1980. Detection and assay of xylanolytic enzymes in a Cellulomonas isolate. Biotechnol. Lett. 2 (8), 363-368.

Sannigrahi, P., Miller, S.J., Ragauskas, A.J., 2010. Effects of organosolv pretreatment and enzymatic hydrolysis on cellulose structure and crystallinity in Loblolly pine. Carbohydr. Res. 345 (7), 965-970.

Scully, D.S., Jaiswal, A.K., Abu-Ghannam, N., 2016. An investigation into spent coffee waste as a renewable source of bioactive compounds and industrially important sugars. Bioengineering 3 (4), 33.

Shannon, E., Jaiswal, A.K., Abu-Ghannam, N., 2018. Polyphenolic content and antioxidant capacity of white, green, black, and herbal teas: a kinetic study. Food Res. 2 (1), 1-11.

Sivasangar, S., Taufiq-Yap, Y.H., Zainal, Z., Kitagawa, K., 2013. Thermal behavior of 
lignocellulosic materials under aerobic/anaerobic environments. Int. J. Hydrog. Energy 38 (36), 16011-16019.

Sluiter, A., Hames, B., Ruiz, R., Scarlata, C., Sluiter, J., Templeton, D., 2006.

Determination of Sugars, Byproducts, and Degradation Products in Liquid Fraction Process Samples. National Renewable Energy Laboratory, Golden.

Sun, F., Chen, H., 2008. Organosolv pretreatment by crude glycerol from oleochemicals industry for enzymatic hydrolysis of wheat straw. Bioresour. Technol. 99 (13), 5474-5479.

Xu, N., Zhang, W., Ren, S., Liu, F., Zhao, C., Liao, H., Xu, Z., Huang, J., Li, Q., Tu, Y., 2012.
Hemicelluloses negatively affect lignocellulose crystallinity for high biomass digestibility under $\mathrm{NaOH}$ and $\mathrm{H}_{2} \mathrm{SO}_{4}$ pretreatments in Miscanthus. Biotechnol. Biofuels 5 (1), 58.

Zhao, X., Cheng, K., Liu, D., 2009. Organosolv pretreatment of lignocellulosic biomass for enzymatic hydrolysis. Appl. Microbiol. Biotechnol. 82 (5), 815.

Zuorro, A., 2015. Optimization of polyphenol recovery from espresso coffee residues using factorial design and response surface methodology. Sep. Purif. Technol. 152, 64-69. 


\section{Update}

\section{Bioresource Technology Reports}

Volume 11, Issue, September 2020, Page

DOI: https://doi.org/10.1016/j.biteb.2020.100500 


\section{Erratum regarding previous published articles}

Owing to a Publisher error Declaration/Conflict of Interest statements were not included in the published versions of the following articles that appeared in previous issues of Bioresource Technology Reports.

The appropriate Declaration/Conflict of Interest statements, provided by the Authors are included below.

1. "Synthesis of sulfonated carbon catalyst from waste orange peel for cost effective biodiesel production" (Bioresource Technology Reports, 2018; 2: 69-76) https://doi.org/10.1016/j.biteb.2018.04. 007

Conflict of Interest: The Authors wish to confirm that there are no known conflicts of interest associated with this publication and there has been no significant financial support for this work that could have influenced its outcome.

2. "Comparative analysis of banana waste bioengineering into animal feeds and fertilizers" (Bioresource Technology Reports, 2018; 2: 107-114) https://doi.org/10.1016/j.biteb.2018.04.008

Conflict of Interest: The Authors wish to confirm that there are no known conflicts of interest associated with this publication.

3. "Evaluating the Water Quality Impacts of Hydrothermal Liquefaction Assessment of Carbon, Nitrogen, and Energy Recovery" (Bioresource Technology Reports, 2018; 2: 115-120) https://doi. org/10.1016/j.biteb.2018.04.010

Conflict of Interest: The Authors wish to confirm that there are no known conflicts of interest associated with this publication and there has been no significant financial support for this work that could have influenced its outcome.

4. "Misuse of pre-exponential factor in the kinetic and thermodynamic studies using thermogravimetric analysis and its implications" (Bioresource Technology Reports, 2018; 2: 88-91) https://doi.org/ 10.1016/j.biteb.2018.04.011

Conflict of Interest: The Authors wish to confirm that there are no known conflicts of interest associated with this publication and there has been no financial support for this work that could have influenced its outcome.

5. "Use of grape pomace as a biosorbent for the removal of the Brown
KROM KGT dye" (Bioresource Technology Reports, 2018; 2: 92-99) https://doi.org/10.1016/j.biteb.2018.05.001

Conflict of Interest: No conflict of interest exists.

6. "Enhanced ethyl levulinate production from citrus peels through an in-situ hydrothermal reaction" (Bioresource Technology Reports, 2018; 2: 84-87) https://doi.org/10.1016/j.biteb.2018.05.002

Conflict of Interest: The Authors wish to confirm that there are no known conflicts of interest associated with this publication and there has been no significant financial support for this work that could have influenced its outcome.

7. "Xylooligosaccharides production by fungi cultivations in rice husk and their application as substrate for lactic acid bacteria growth" (Bioresource Technology Reports, 2018; 2: 100-106) https://doi. org/10.1016/j.biteb.2018.05.004

Conflict of Interest: The Authors wish to confirm that there are no known conflicts of interest associated with this publication and there has been no significant financial support for this work that could have influenced its outcome.

8. "Sewage sludge and food waste co-digestion to methane: A multi response and kinetic modeling study to evaluate the dynamics in compositional parameters" (Bioresource Technology Reports, 2018; 2: 121-130) https://doi.org/10.1016/j.biteb.2018.05.005

Conflict of Interest: The Authors have no interests to declare.

9. "Optimisation of organosolv pretreatment for the extraction of polyphenols from spent coffee waste and subsequent recovery of fermentable sugars" (Bioresource Technology Reports, 2018; 3: 7-14) https://doi.org/10.1016/j.biteb.2018.05.009

Conflict of Interest: The Authors wish to confirm that there are no known conflicts of interest associated with this publication and there has been no significant financial support for this work that could have influenced its outcome.

10. "Production of compounds by phytopathogenic fungi for biological control of aquatic macrophytes" (Bioresource Technology Reports, 2018; 3: 22-26) https://doi.org/10.1016/j.biteb.2018.05.012 Conflict of Interest: The Authors have no interests to declare. 